\title{
Synthesis, Characterization and Optical Limiting Properties of Novel Ball-type Four tert-Butylcalix[4]arene Bridged Double-decker Lutetium(III) and Indium(III) Phthalocyanines
}

\author{
Tanju Ceyhan, ${ }^{\mathrm{a}}$ Gül Yağlioğlu, ${ }^{\mathrm{b}}$ Hüseyin Ünver, ${ }^{\mathrm{c}}$ Bekir Salih, $^{\mathrm{d}}$ Mehmet K. Erbil ${ }^{\mathrm{a}}$ \\ Ayhan Elmali, ${ }^{\mathrm{b}}$ and Özer Bekaroğlu ${ }^{\mathrm{e} @}$ \\ a Department of Biochemistry, Division of Organic Chemistry, Gülhane Medical Academy, (GATA), Ankara, Turkey \\ ${ }^{\mathrm{b}}$ Department of Engineering Physics, Faculty of Engineering, Ankara University, Ankara, Turkey. \\ ${ }^{c}$ Department of Physics, Faculty of Sciences, Ankara University, Ankara, Turkey. \\ ${ }^{\mathrm{d}}$ Department of Chemistry, Hacettepe University, 06532 Ankara, Turkey. \\ ${ }^{\mathrm{e}}$ Department of Chemistry, Technical University of Istanbul, 80626, Maslak, Istanbul, Turkey. \\ ${ }^{@}$ Corresponding authorE-mail: obek@itu.edu.tr
}

\begin{abstract}
Novel ball type four tert-butylcalix[4]arene bridged double-decker lutetium(III) phthalocyanine [LuPc $c_{2}\left(\right.$ tbca $\left._{4}\right] 2$ which exhibit nonlinear optical limiting behaviour and indium(III) phthalocyanine [InP $\left.c_{2}(t b c a)_{4}\right] 3$ were prepared by the reaction of 1,3-bis(3,4-dicyanophenoxy)-4-tert-butylcalix[4]arene 1 and the corresponding metal salts $\left(\mathrm{Lu}(\mathrm{OAc})_{3} \cdot 3 \mathrm{H}_{2} \mathrm{O}\right.$ and $\left.\mathrm{InCl}_{3}\right)$ in the presence of lithium metal in 1-pentanol. Newly synthesized phthalocyanines were characterized by elemental analysis, UV-vis, IR, MALDI-TOF MS and ${ }^{1} H$ NMR spectra.
\end{abstract}

\section{Introduction}

Calix[4]arenes are versatile host molecules for supramolecular chemistry, which have been incorporated into numerous elaborate structures. ${ }^{[1]}$ Double calix[4]arenes $^{[2]}$ for example, have been constructed covalently through upper rim/upper rim linkage, ${ }^{[3]}$ lower rim/lower rim linkage ${ }^{[4]}$ or upper rim/lower rim linkage ${ }^{[5]}$ and also noncovalently through hydrogen bonding. ${ }^{[6]}$ Thus a large number of calixarene derivatives with defined cavity and function have been designed and synthesized allowing efficient and selective complexation with various species. ${ }^{[7]}$ More importantly, calixarenes provide building blocks for more complex architectures. ${ }^{[2,8]}$ Assemblies of two calix[n]arenes via both upper rims, head-to-head using covalently bonded spacers such as aromatic chains ${ }^{[9]}$ and porphyrins $^{[10]}$ have lead to molecular capsules with enforced cavity. The resulting molecular capsules were capable of encapsulating a number of aromatic molecules. ${ }^{[11]}$ Based on the intrinsic cavity of calix[4]arene and its hydrophobic and $\mathrm{CH}-\pi$ interactions ${ }^{[12]}$ with guest substrates we envisaged that oligomeric calix[4]arenes would provide novel and efficient receptors to complex larger and more complicated organic molecules such as phthalocyanines. This led us to undertake this investigation.

Phthalocyanines (Pcs) are one of the major types of tetra-pyrrole derivatives showing a practical applications in a wide range of high technology fields such as nonlinear optics, photosensitizers, gas sensors, catalysts, liquid crystals, optical data storage, sensitizers for photodynamic therapy of cancer, electrodes in fuel cell, photoelectric conversion materials in solar cells and laser service substances, among others. ${ }^{[13-15]}$ A great number of remarkable applications of phthalocyanines arise from their unique $18 \pi$ electron conjugated aromatic cloud which makes them present high thermal and chemical stability and remarkable photoelectric properties. ${ }^{[16]}$ The exceptional chemical and physical properties of these compounds can be due to various substituents on the phenyl rings. Much research on this concept has been devoted to the synthesis of phthalocyanines that have been peripherally functionalized with appendages that can coordinate metal cations.

Diphthalocyaninates of rare-earth metals, especially the lutetium derivative, have become objects of intense investigations. The interest for compounds of this kind, first due to their electrochromic properties, ${ }^{[17-19]}$ is actually increasing because of their unusual conductivity. ${ }^{[20-23]}$ Substituents on the periphery of a macrocycle ring like a phthalocyanine are known to affect its physicochemical properties. Many relationships between the chemical structure and properties like photoconductivity, ${ }^{[24]}$ electrocrystallization ${ }^{[25]}$ and redox potentials ${ }^{[26]}$ have been established. Chemical groups linked to the peripheral benzene rings not only modify the electronic properties of the phthalocyanines, but also those of the materials obtained from these molecular units. ${ }^{[27,28]}$

We have reported on the synthesis, characterization of novel $s$-triazines bearing three oxygen-linked metallo Pcs and lutetium bisphthalocyanine sandwich complexes. ${ }^{[29,30]}$ Synthesis, characterization, conduction and gas sensing properties of novel multinuclear metallo Pcs with alkylthio substituents were also reported in the literature. ${ }^{[31]}$ In our previous study, we achieved for the first time the synthesis of a novel ball-type four tert-butylcalix[4]arene bridged binuclear zinc(II) Pc. This novel compound exhibited mixed-valence behaviour and non-Arrhenius type dependence of conductivity. ${ }^{[32]}$ We have reported recently on the synthesis, characterization, and electrochemical, electrical and gas sensing properties of a novel tert-butylcalix[4]arene bridged bis double-decker lutetium (III) phthalocyanine. ${ }^{[33]}$ 
Hereafter we report for the first time, the synthesis and characterization of a novel ball type four tert-butylcalix[4]arene bridged double-decker lutetium(III) 2 and indium(III) 3 phthalocyanines (Scheme 1). We also present the results of nonlinear optical limiting measurements. On the other hand, the importance of this new type of phthalocyanine may be regarded as an important step in that it may be one of the candidates for optical limiting applications.

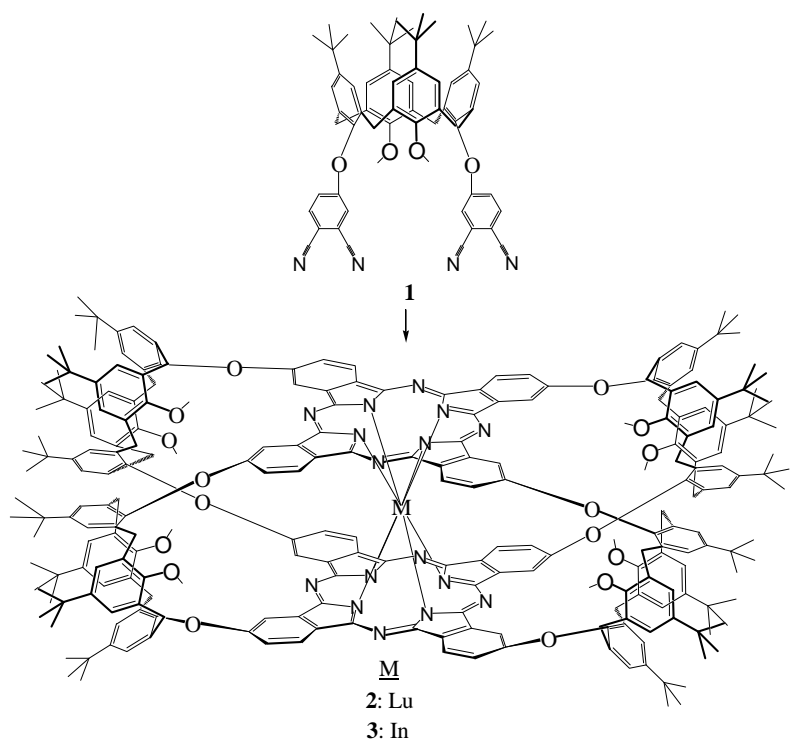

Scheme 1. Synthesis of compounds 2 and $\mathbf{3}$.

\section{Experimental}

All reagents and solvents were of reagent-grade quality obtained from commercial suppliers. The solvents were stored over molecular sieves (4 $\AA$ ). Compound 1 was prepared according the literature method ${ }^{[32]}$ Routine IR were recorded on a Shimadzu IR-470 Infrared spectrometer as $\mathrm{KBr}$ pellets, electronic spectra on a UNICAM UV 500 UV-vis spectrometer. Elemental analysis was performed by the LECO CHNS 932 in the Instrumental Analysis Laboratory of TUBITAK Ankara Research Center. ${ }^{1} \mathrm{H}$ NMR spectra were recorded on a Bruker Avance DPX-400 spectrometer. Mass spectra were acquired on a Voyager-DETM PRO MALDI-TOF mass spectrometer (Applied Biosystems, USA) equipped with a nitrogen UV-Laser operating at $337 \mathrm{~nm}$. Spectra were recorded both in linear and reflection modes with average of 50 shots. 3-Indolylacrylic acid (IAA) MALDI matrix was used and prepared in chloroform at concentration of $20 \mathrm{mg} / \mathrm{ml}$ for Pcs 2 and $\mathbf{3}$ as the most efficient matrix. MALDI samples were prepared by mixing sample solutions $(4 \mathrm{mg} / \mathrm{ml}$, in acetic acid) with the matrix solution $(1: 10 \mathrm{v} / \mathrm{v})$ in a $0.5 \mathrm{ml}$ eppendorf ${ }^{\circledR}$ micro tube. Finally $1 \mu \mathrm{l}$ of this mixture was deposited on the sample plate, dried at room temperature and then analyzed.

\section{Syntheses}

Reaction procedure for $\left[\mathrm{LuPc}_{2}(\text { tbca })_{4}\right](2)$. Clean lithium metal $(50 \mathrm{mg}, 7.355 \mathrm{mmol})$ was placed in a glass tube with $2 \mathrm{ml}$ of 1-pentanol and the mixture was purged with nitrogen, sealed and refluxed until the complete reaction of lithium. Then, the glass tube was opened and compound 1 (200 $\mathrm{mg}, 0.215 \mathrm{mmol}$ ) was added and the tube was sealed again. The mixture was refluxed for another $1 \mathrm{~h}$, then $\mathrm{Lu}(\mathrm{OAc})_{3} \cdot 3 \mathrm{H}_{2} \mathrm{O}(75.6 \mathrm{mg}, 0.215 \mathrm{mmol})$ was added, the tube was sealed again and the mixture refluxed for additional $15 \mathrm{~h}$. After cooling to room temperature, $10 \mathrm{ml}$ of ethanol was added to the dark green mixture to precipitate the product. The precipitate was suction filtered, multiply washed first with hot water and then with hot ethanol, hot methanol, chloroform, hot DMF, hot ethyl acetate and THF and then dried in vacuum to give the pure product. This compound is soluble in acetic acid and in the mixture of acetic acid-DMSO. Yield: $38 \mathrm{mg}$, $18 \%$. m.p. $>300{ }^{\circ} \mathrm{C}$. UV-vis $\left(\mathrm{CH}_{3} \mathrm{COOH}, 106.08 \mu \mathrm{M}\right): \lambda_{\max }, \mathrm{nm}$

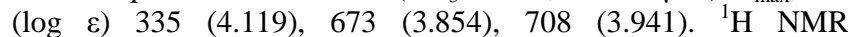
$\left(\mathrm{CD}_{3} \mathrm{CO}_{2} \mathrm{D}\right): \delta$, ppm 7.83-6.91 (m, 56H, Ar-H ), $3.87(\mathrm{~s}, 24 \mathrm{H}$, $\left.\mathrm{OCH}_{3}\right), 3.76\left(\mathrm{~d}, J=13.4 \mathrm{~Hz}, 16 \mathrm{H}, \mathrm{ArCH}_{2} \mathrm{Ar}\right), 3.28(\mathrm{~d}, J=13.4 \mathrm{~Hz}$, $\left.16 \mathrm{H}, \mathrm{ArCH}_{2} \mathrm{Ar}\right), 1.49(\mathrm{~s}, 72 \mathrm{H}, t-\mathrm{Bu}), 0.98(\mathrm{~s}, 72 \mathrm{H}, t$-Bu). IR (KBr): v, $\mathrm{cm}^{-1} 3054$ (CH Ar), 2922-2836 (CH aliph.), 2328, 1727, 1654, 1612 (C=C Ar), 1470, 1358, 1290 (Ar-O-Ar), 1192, 1116, 945, 872, 758, 672, 619. MS (MALDI-TOF): $\mathrm{m} / \mathrm{z} 3888[\mathrm{M}+\mathrm{H}]^{+}$. Anal calc. for $\mathrm{C}_{248} \mathrm{H}_{256} \mathrm{~N}_{16} \mathrm{O}_{16} \mathrm{Lu}$ (3887): C 76.56, H 6.58, N 5.76; found: C 76.12, H 6.21, N 5.84.

Reaction procedure for $\left[\operatorname{InPc}_{2}(\text { tbca })_{4}\right](3)$. Clean lithium metal $(50 \mathrm{mg}, 7.355 \mathrm{mmol}$ ) was placed in a glass tube with $2 \mathrm{ml}$ of 1-pentanol and the mixture was purged with nitrogen, sealed and refluxed until the complete dissolution of lithium. Then, the glass tube was opened and compound $\mathbf{1}(200 \mathrm{mg}, 0.215 \mathrm{mmol})$ was added and the tube was sealed again and the mixture was refluxed for another $1 \mathrm{~h}$. Then $\mathrm{InCl}_{3}(47.7 \mathrm{mg}, 0.215 \mathrm{mmol})$ was added, the tube was sealed again and the mixture was refluxed for a further $15 \mathrm{~h}$. After cooling to room temperature, $10 \mathrm{ml}$ of ethanol was added to the dark green mixture to precipitate the product. The same purification process was carried out as described for compound 2. This compound is soluble in acetic acid and in the mixture of acetic acid-DMSO. Yield: $117 \mathrm{mg}, 57 \%$. m.p. $>300^{\circ} \mathrm{C}$. UV-vis $\left(\mathrm{CH}_{3} \mathrm{COOH}, 92.62 \mu \mathrm{M}\right): \lambda_{\max }, \mathrm{nm}(\log \varepsilon) 346$ (4.475), 634 (3.976), 702 (4.461). ${ }^{1} \mathrm{H}$ NMR $\left(\mathrm{CD}_{3} \mathrm{CO}_{2} \mathrm{D}\right): \delta$, ppm 7.92-7.02 (m, 56H, Ar-H ), $3.72\left(\mathrm{~s}, 24 \mathrm{H}, \mathrm{OCH}_{3}\right), 3.37$ (d, $J=13.4$ $\mathrm{Hz}, 16 \mathrm{H}, \mathrm{ArCH}_{2} \mathrm{Ar}$ ), 3.28 (d, J=13.4 Hz, 16H, $\mathrm{ArCH}_{2} \mathrm{Ar}$ ), 1.49 (s, $72 \mathrm{H}, t$-Bu), 0.98 (s, 72H, $t$-Bu). IR (KBr): $v, \mathrm{~cm}^{-1} 3042$ (CH Ar), 2936-2872 (CH aliph.), 2326, 1730, 1655, 1615 (C=C Ar), 1470, 1357, 1292 (Ar-O-Ar), 1190, 1116, 945, 870, 761, 670, 620. MS (MALDI-TOF): $\quad \mathrm{m} / \mathrm{z} \quad 3828 \quad[\mathrm{M}+\mathrm{H}]^{+}$. Anal calc. for $\mathrm{C}_{248} \mathrm{H}_{256} \mathrm{~N}_{16} \mathrm{O}_{16}$ In (3827): C 77.76, H 6.68, N 5.85; found: $\mathrm{C}$ 77.22, H 6.70, N 6.02.

\section{Results and Discussions}

\section{Syntheses and Characterization}

The unsubstituted $\mathrm{LuPc}_{2}$ derivatives are usually prepared by cyclic tetramerization of phthalonitrile in the presence of lanthanide salts. ${ }^{[34]}$ The symmetrically substituted diphthalocyanines has also been obtained by this way. ${ }^{[35]}$ The compounds prepared by following this synthetic route are always obtained in very poor yields, a few percents; moreover the purification is a major problem. Some operations like sublimation, ${ }^{[36]}$ or column chromatography $^{[37]}$ have been used to increase the purity of the complex. Both these methods are quite unsatisfactory for a complete separation from the impurities since the unreacted phthalonitrile aggregates to the rare-earth metal diphthalocyaninates and both are eluted simultaneously during column chromatography. In another synthetic method, ${ }^{[38]}$ the same reactants are heated in a solvent in the presence of DBU (1,8-diazabicyclo[5.4.0]undec-7-ene), a catalyst which favours the macrocycle formation. In this latter case, the yield of the desired phthalocyanine is also low and often inferior to $2 \%$, the major product being the monophthalocyanine derivative of $\mathrm{LuPc}(\mathrm{OAc})$. However, a series of homoleptic sandwich complexes of 
2,3,9,10,16,17,23,24-octakis(octyloxy)phthalocyanine with rare earth metals $\left\{\mathrm{M}\left[\mathrm{Pc}\left(\mathrm{OC}_{8} \mathrm{H}_{17}\right)_{8}\right]_{2}(\mathrm{M}=\mathrm{La}, \mathrm{Pr}, \mathrm{Nd}, \mathrm{Sm}\right.$, $\mathrm{Eu}, \mathrm{Gd}, \mathrm{Tb}, \mathrm{Dy}, \mathrm{Y}, \mathrm{Ho}, \mathrm{Er}, \mathrm{Tm})$ and $\mathrm{HCe}\left[\mathrm{Pc}\left(\mathrm{OC}_{8} \mathrm{H}_{17}\right)_{8}\right]_{2}$ \} has been prepared by the cyclic tetramerization of 4,5di(octyloxy)phthalonitrile on the template of $\mathrm{M}(\mathrm{acac})_{3} \cdot n \mathrm{H}_{2} \mathrm{O}$ in the presence of DBU in better yields. ${ }^{[39]}$

Dilithium phthalocyanines $\left[\mathrm{Li}_{2} \mathrm{Pc}\right]$ are interesting materials for the preparation of substituted diphthalocyanines obtained by condensation of substituted macrocycle units. Thus, in the first step of our synthetic process, dilithium phthalocyanine was prepared by condensation of phthalodinitrile $\mathbf{1}$ in lithium pentane-1-olate in 1-pentanol which readily took place at reflux temperature. Treatment of the reaction mixture in situ with lutetium acetate and indium chloride gave novel ball type four tert-butylcalix[4]arene bridged double decker lutetium(III) phthalocyanine $\mathbf{2}$ and indium(III) phthalocyanine $\mathbf{3}$, respectively (Scheme 1).

Characterization of the new products involved a combination of methods including elemental analysis, IR, UV-vis, MALDI-TOF MS and ${ }^{1} \mathrm{H}$ NMR spectroscopic techniques. The spectroscopic data of the new compounds were in accordance with the structures. IR spectroscopy has been proved useful in characterisation of the nature of the phthalocyanine ligand in tetrapyrrole sandwich complexes. The IR spectra of Lu ${ }^{\text {III }}$ complex $\mathbf{2}$ and In $^{\text {III }}$ complex $\mathbf{3}$ closely resembles those of the reduced double-deckers of tervalent rare earth metals $\left[\mathrm{M}^{\mathrm{III}}\left(\mathrm{Pc}^{-2}\right)_{2}\right]^{-}{ }^{[40]}$ which also demonstrate the dianionic nature of the phthalocyanine rings in both compounds. The marker IR band for the phthalocyanine monoanion radical, $\mathrm{Pc}^{*-}$ appearing at 1310$1320 \mathrm{~cm}^{-1}$ in the IR spectra was not seen for both compounds 2 and 3. This indicates that both phthalocyanine rings exist as dianions in $\mathrm{H}\left[\mathrm{M}^{\mathrm{III}}\left(\mathrm{Pc}^{-2}\right)_{2}\right](\mathrm{M}=\mathrm{Lu}, \mathrm{In})$. The IR spectra taken in $\mathrm{KBr}$ pellets showed $\mathrm{CH}$ aliphatic peaks at $2922-2836 \mathrm{~cm}^{-1}$ and $2936-2872 \mathrm{~cm}^{-1}$, while aromatic $\mathrm{C}=\mathrm{C}$ peak at 1612 and $1615 \mathrm{~cm}^{-1}$ and aromatic $\mathrm{CH}$ peaks at 3054 and $3042 \mathrm{~cm}^{-1}$ for $\mathbf{2}$ and $\mathbf{3}$, respectively. Comparison of the IR spectral data of compound $\mathbf{1}$ with compounds $\mathbf{2}$ and $\mathbf{3}$ clearly confirmed the formation of desired compounds by the disappearance of sharp absorption band attributable to $\mathrm{C} \equiv \mathrm{N}$ group at $2229 \mathrm{~cm}^{-1[32]}$ for $\mathbf{1}$. The absorptions at 1290 and $1292 \mathrm{~cm}^{-1}$ indicated the presence of Ar-O-Ar groups in the structure for $\mathbf{2}$ and $\mathbf{3}$, respectively.

Only a few NMR data concerning bis(phthalocyaninates) of rare earth elements are available from the literature ${ }^{[41,42]}$ most of them dealing with the reduced forms. ${ }^{[43,44]}$ Reduced form of both compounds enabled us to record satisfactory ${ }^{1} \mathrm{H}$ NMR data. The ${ }^{1} \mathrm{H}$ NMR spectra for both compounds indicate that the two phthalocyanine rings exist as dianions. Compounds $\mathbf{2}$ and $\mathbf{3}$ gave the ${ }^{1} \mathrm{H}$ NMR spectra which are very similar to each other as they have similar structure. In the ${ }^{1} \mathrm{H}$ NMR spectra which were taken in $\mathrm{CD}_{3} \mathrm{CO}_{2} \mathrm{D}$, the aromatic protons appeared at 7.83-6.91 and 7.92-7.02 ppm as multiplets for compounds $\mathbf{2}$ and $\mathbf{3}$, respectively. Observations of singlet peaks at 3.87 and 3.72 ppm indicated the presence of methoxy protons in the structures of compounds $\mathbf{2}$ and $\mathbf{3}$, respectively. Compounds $\mathbf{2}$ and $\mathbf{3}$ adopted a cone conformation, which was evidenced by the $\mathrm{AB}$ system of the methylene protons within calix[4]arene units with a pair of $\mathrm{AB}$ type doublets observed for the methylene $\left(\mathrm{ArCH}_{2} \mathrm{Ar}\right)$ protons at 3.76 and $3.28 \mathrm{ppm}$ in $\mathbf{2}$ and 3.37 and $3.28 \mathrm{ppm}$ in $\mathbf{3}$, with a coupling constant of $13.4 \mathrm{~Hz}$. The non-equivalance of terminal calix[4]arenes with the middle one(s) was further demonstrated by the observation of two singlets of tert-butyl groups at 1.49 and $0.98 \mathrm{ppm}$ with proton ratio of $72: 72$ for both compounds 2 and $\mathbf{3}$.

Positive ion MALDI-MS spectra of $\mathbf{2}$ and $\mathbf{3}$ are given in Figure 1 and Figure 2, respectively. Many different MALDI matrixes were tried to find intense molecular ion peak and low fragmentation under the MALDI-MS conditions for these compounds. Only 3indolylacrylic acid yielded good MALDI-MS spectra as seen in Figures 1 and 2.

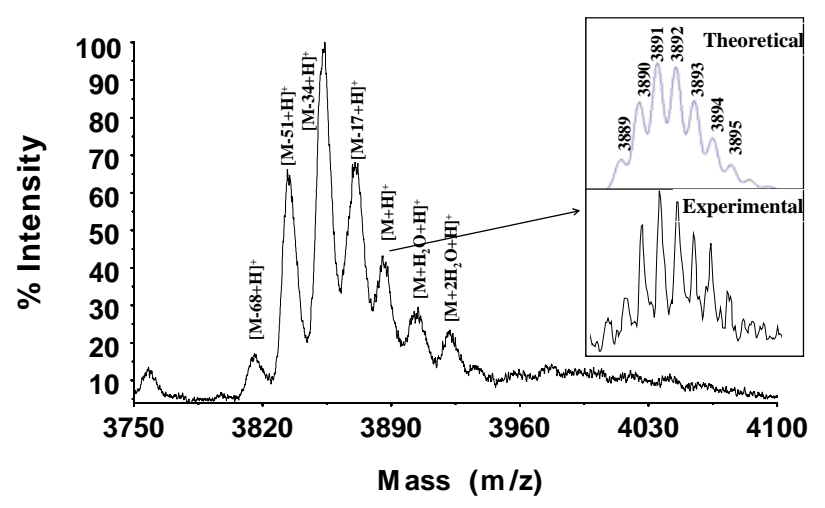

Figure 1. MALDI-MS spectrum of compound 2.

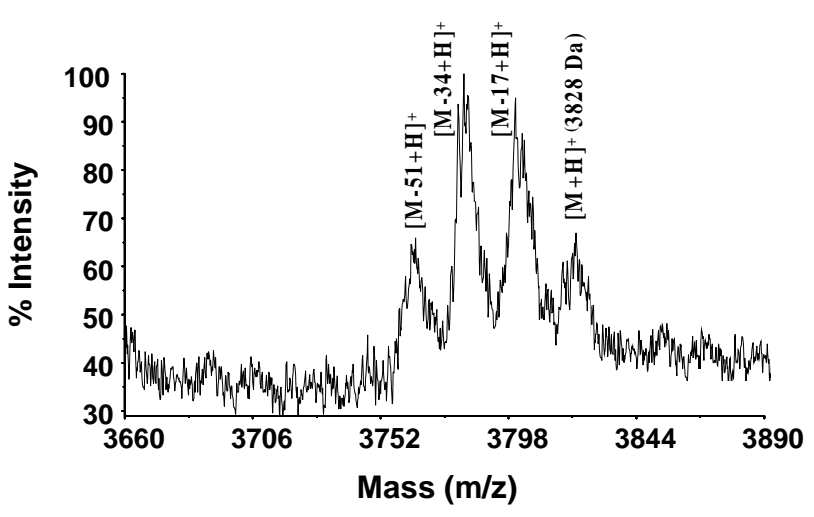

Figure 2. MALDI-MS spectrum of compound 3.

Protonated molecular ion peak of 2 was observed at 3889, having isotopic distribution between 3889 and 3896 Da masses, with two adduct peaks and four fragment ion peaks together (Figure 1). Two adduct peaks are resulted from the one and two moles of water adducts to the protonated molecular ion peak of $\mathbf{2}$ showing the easy water coordination.

Protonated etheric oxygen $\underset{\left.\mathrm{R}-\mathrm{O}-\mathrm{CH}_{3}\right)}{\mathrm{H}}$ on the side aromatic ring could be rearranged and the $-\mathrm{OH}$ group leaves from the protonated molecule with $\mathrm{CH}_{3}$ migration to the side aromatic chains. In this way, $-\mathrm{OH}$ leaving from the main protonated molecule could be followed. So, the mass difference between the fragment ion peaks corresponding $17 \mathrm{Da}$ results from the $-\mathrm{OH}$ group elimination on the ligand at the side etheric groups. The inset in Figure 1 shows the theoretical and the experimental isotopic distribution of compound 2 . It is clearly shown that isotopic mass 
distribution of compound $\mathbf{2}$ is exactly overlapped with the experimental isotopic mass distribution of $\mathbf{2}$ obtained in the positive ion reflection mode. When the UV-vis spectrum of compound $\mathbf{2}$ in acetic acid was investigated, some pecularities were observed. UV-vis spectrum of $\mathbf{2}$ resembles the spectrum of metal free phthalocyanines. In order to control whether the $\mathrm{Lu}^{\text {III }}$ complex $\mathbf{2}$ undergoes demetallation in acetic acid, it was dissolved completely in of acetic acid $(10 \mathrm{mg}$ in $1 \mathrm{ml})$ and about $1 \mathrm{ml}$ of diionized water was then added into the solution drop by drop. After the addition of water, precipitation was occurred. Supernatant over the precipitate was removed and precipitate was dried in vacuum oven at $35^{\circ} \mathrm{C}$ for $5 \mathrm{~h}$ at $17 \mathrm{mT}$ Trr pressure. Dried precipitate was redissolved again in $0.5 \mathrm{ml}$ acetic acid and positive ion and linear mode MALDI-MS spectrum of this redissolved species was recorded with average of 50 laser shots using the IAA matrix. Both MALDI-MS spectra obtained in acetic acid initially and after reprecipitation were found to be identical. No metal free form of that complex after dissolving in acetic acid and reprecipitation with water addition was observed in MALDI-MS. This shows high stability of the Lu ${ }^{\text {III }}$ complex 2 in acetic acid.

Positive ion and linear mode MALDI mass spectrum of $\mathbf{3}$ is given in Figure 2. In the case of $\mathbf{3}$, no water adduct peak(s) was observed but only three fragment ion peaks appeared in the MALDI-MS spectrum of $\mathbf{3}$ beside the intense protonated molecular ion peak at 3828 Da mass. Absence of the water adduct(s) peaks show that their stability in the case of $\mathbf{3}$ is less when compared to that of $\mathbf{2}$. The mass difference between the protonated molecular ion peak and the following fragments of $\mathbf{3}$ again is $17 \mathrm{Da}$ due to elimination of the $-\mathrm{OH}$ group from the side etheric moieties on the ligand. All of the results show that compounds $\mathbf{2}$ and 3 were synthesized perfectly.

Figure 3 presents the UV-vis spectra of the compounds 2 and $\mathbf{3}$ in acetic acid. In the visible region, the absorption spectra for both compounds in acetic acid shows distinct characteristic bands by $670-710 \mathrm{~nm}$ corresponding to the $Q$ absorption bands with vibration overtones at shorter wavelength. The characteristic $Q$-bands attributed to the $\pi \rightarrow \pi^{*}$ transitions from the highest occupied molecular orbital (HOMO) to the lowest unoccupied molecular orbital (LUMO) of the Pc ring are responsible for the colour of the compound. ${ }^{[48]}$ For the compound 2, similar to the literature data, ${ }^{[39,49]}$ the $Q$-band appears at $708 \mathrm{~nm}$ as a strong absorption with a vibration overtone of comparable intensity at $673 \mathrm{~nm}$. For compound 3, the most intensive band is the $Q$ band at $702 \mathrm{~nm}$ with a vibronic band at 634 $\mathrm{nm}$. The spectral features are different from those of phthalocyanine analogues in the neutral form $\mathrm{M}^{\mathrm{III}}\left(\mathrm{Pc}^{-2}\right)\left(\mathrm{Pc}^{--}\right)$, but resembles those of the anionic $\left[\mathrm{M}^{\mathrm{III}}(\mathrm{Pc})_{2}\right]^{-}$and $\mathrm{HM}^{\mathrm{III}}(\mathrm{Pc})_{2}$ due to their similar electronic structure. ${ }^{[45-47]}$ This is supported by the fact that the UV-vis absorption of the band around 450-510 nm characteristic for $\pi$-radicals was not observed for both compounds.

Additionally, compounds $\mathbf{2}$ and $\mathbf{3}$ show a typical Soret band ( $B$-band) absorption arising from the deeper $\pi \rightarrow$ LUMO transitions in UV region at 335 and $346 \mathrm{~nm}$, respectively. The position of all bands is metal dependent, indicating the existence of the $\pi-\pi$ interaction between the phthalocyanine ligands. The decrease in the ionic radius of metal leads to the blue shift of the $Q$-bands in the spectra. ${ }^{[50]}$

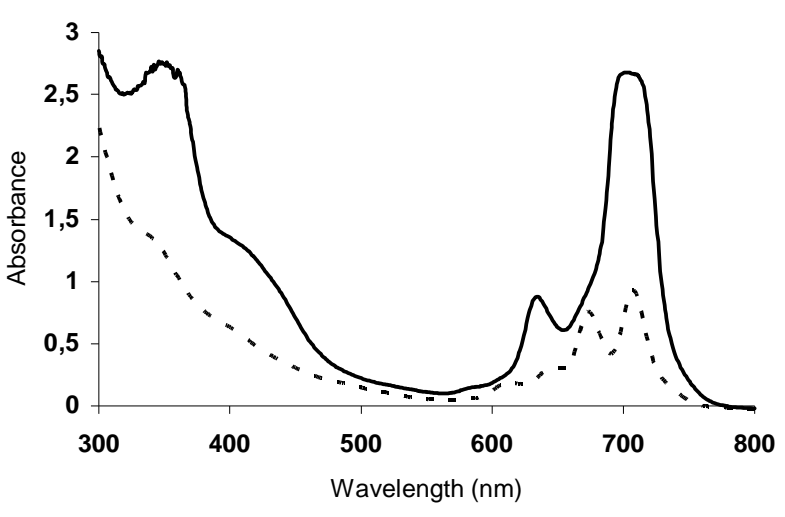

Figure 3. UV-vis spectra for compounds 2 (dashed line) and $\mathbf{3}$ (solid line) in acetic acid. Concentration $\approx 1 \cdot 10^{-4} \mathrm{M}$.

The energies and relative intensities and broadening of the bands observed are in accordance with the pattern that would be anticipated on the basis of excitation coupling theory for the phthalocyanines. ${ }^{[51]}$

\section{Nonlinear Absorption and Optical Limiting Measurements}

Since the nonlinear optical response of compound $\mathbf{3}$ is neglectable, we only present nonlinear optical properties of compound 2. Nonlinear optical responses were measured by z-scan experiment, ${ }^{[52,53]}$ with a frequency-doubled $(532 \mathrm{~nm})$ Q-switched, mode-locked Nd:YAG laser (Quantel Brillant) at about 4 ns pulse duration. A single nearly Gaussian beam was tightly focused with a $30 \mathrm{~cm}$ focal length lens. The transmittance of a sample was measured at far field with 2 mm diameter aperture (close aperture) and without aperture (open aperture) simultaneously as the sample moves along the propagation direction $(z)$ of the focused beam. From the open aperture $z$-scan experiments at various input fluences it was found that this compound shows considerably large nonlinear absorption. Therefore, the optical limiting experiment was performed with the open aperture mode of the $z$-scan setup by fixing sample position at about the focus and changing the input fluence. The fluence at the sample was adjusted by a combination of neutral-density filters. The sample was prepared in acetic acid and DMSO solution (1:1) at $2.9 \cdot 10^{-3} \mathrm{M}$ concentration which yields $82 \%$ linear transmittance. The absorption coefficient is $0.9 \mathrm{~cm}^{-1}$ at $532 \mathrm{~nm}$.

The open-aperture $z$-scan performed in this study showed intensity dependent absorption (i.e. nonlinear absorption) of the incident light. It is assumed to be due to reverse saturable excited state absorption (RSA) in phthalocyanines. ${ }^{[54]}$ Effective absorption coefficients are calculated using theory reported previously. ${ }^{[53,55]}$ All open aperture $z$-scan data were fitted using nonlinear regression method with the following equation. In the equation, the normalized transmittance is given as a function of position $z$ :

$$
T_{\text {Norm }}(z)=\left[\frac{\log _{e}\left[1+\frac{q_{000}}{1+\left(z / z_{0}\right)^{2}}\right]}{\frac{q_{000}}{1+\left(z / z_{0}\right)^{2}}}\right]
$$


In this equation $z_{0}$ is the diffraction length of the beam and $q_{000}=\beta_{\text {eff }} I_{0} L_{\text {eff }}$, where $L_{\text {eff }}=\frac{1-e^{-(\alpha L)}}{\alpha}$ and $\beta_{\text {eff }}$ is the effective intensity dependent nonlinear absorption coefficient and $I_{0}$ is the intensity of the light at focus. $L_{\text {eff }}$ is known as the effective length of the sample, $\alpha$ is the absorption coefficient, $L$ is the sample thickness. In the equation, the normalized transmittance is given as a function of position $z$.

The beam waist radius $w_{0}$ and the nonlinear absorption coefficient $\beta_{\text {eff }}$ were used as free parameters in the fit. The waist radius $w_{0}$ was found to be almost constant for various input intensities $\left(I_{0}\right)$. The averaged value of $w_{0}$ was found to be $34.2 \mu \mathrm{m}$.

A sample of typical open aperture $z$-scan data is given in Figure 4.

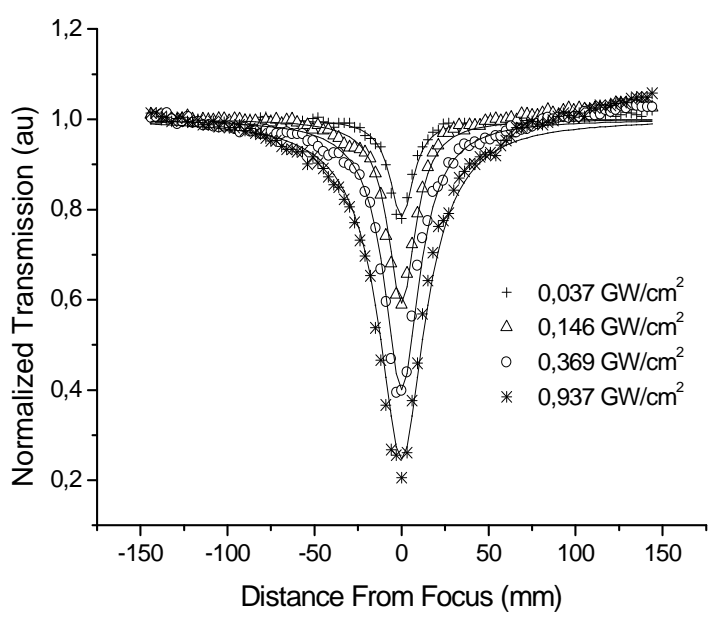

Figure 4. Typical open aperture $z$-scan spectra of compound 2 with normalized transmission plotted as a function of sample position $z$; concentration $=2.9 \cdot 10^{-3} \mathrm{M}$.

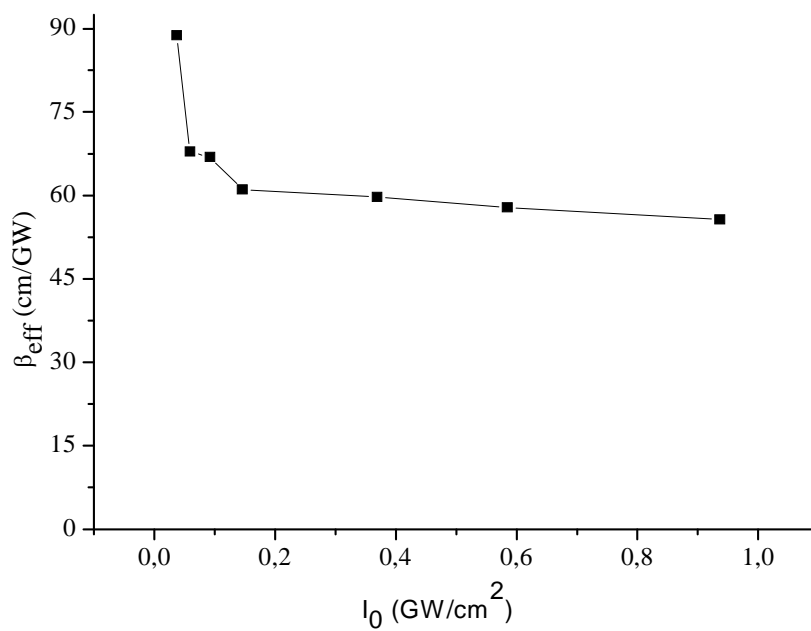

Figure 5. Plot of effective nonlinear absorption coefficient $\beta_{\text {eff }}$ against the on-focus beam intensity $\mathrm{I}_{0}$ for the compound $\mathbf{2}$.

The effective nonlinear absorption coefficients $\beta_{\text {eff }}$ versus on focus intensities were plotted in Figure 5. It is found that the effective nonlinear optical coefficient $\beta_{\text {eff }}$ decreases slightly with increasing beam intensity in Pcs. ${ }^{[56,57]}$ However, as seen from Figure 5, in our case, although there is a sharp decrease of $\beta_{\text {eff }}$ at lower intensities, it becomes almost stable at higher intensities.
For optical limiting applications it is desirable to have stable $\beta_{\text {eff }}$ at high intensities.

Due to the high nonlinear absorption of the sample, we performed optical limiting experiments. The sample was placed at the focus where beam radius is $34.2 \mu \mathrm{m}$. Input fluences versus output fluences were plotted in Figure 6.

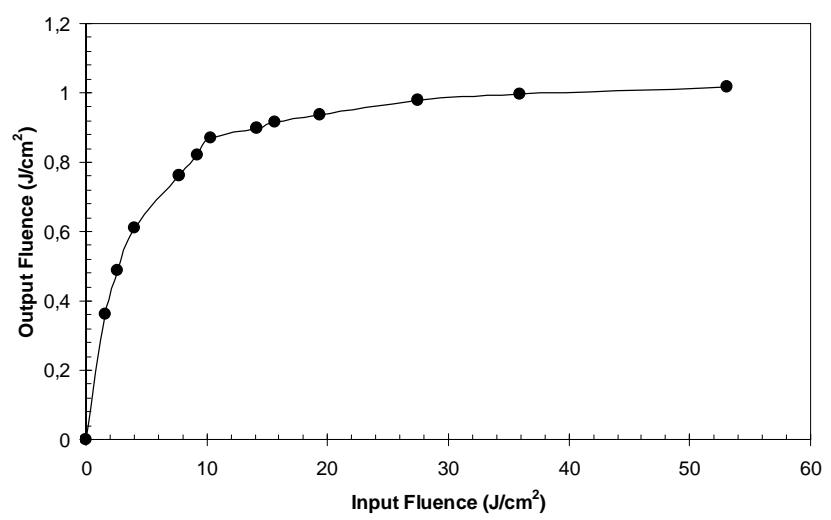

Figure 6. Optical limiting response of the compound 2 at $532 \mathrm{~nm}$; concentration $=2.9 \cdot 10^{-3} \mathrm{M}$.

It is clearly seen that although input fluences increase up to $60 \mathrm{~J} / \mathrm{cm}^{2}$, output fluences remain almost constant at about $1 \mathrm{~J} / \mathrm{cm}^{2}$. This indicates that investigated sample shows good optical limiting behaviour.

\section{Conclusions}

We have presented the synthesis and characterization of novel ball type double-decker lutetium(III) $\left[\mathrm{LuPc}_{2}(\mathrm{tbca})_{4}\right] \quad \mathbf{2}$ and indium(III) phthalocyanine $\left[\mathrm{InPc}_{2}(\mathrm{tbca})_{4}\right] \mathbf{3}$, bridged with four tert-butylcalix[4]arene groups. The phthalocyanines were prepared using a phthalodinitrile derivative of 1,3-dimethoxy-4-tertbutylcalix[4]arene $\mathbf{1}$ and proper materials. The preparations of the new products are supported by elemental analysis, IR, UV-vis, ${ }^{1} \mathrm{H}$ NMR and by MALDI-TOF MS spectra.

Nonlinear absorption and optical limiting experiments were performed with the double-decker $\mathrm{Lu}^{\text {III }}$ phthalocyanine $\left[\mathrm{LuPc}_{2}(\mathrm{tbca})_{4}\right]$ 2. From the open aperture $z$ scan experiments at various input fluences we found that this compound shows considerably large intensity dependent absorption (i.e. nonlinear absorption) of the incident light and although there is a sharp decrease of $\beta_{\text {eff }}$ at lower intensities, it becomes almost stable at higher intensities. The optical limiting experiments performed with compound 2, clearly shows that although input fluences increase up to $60 \mathrm{~J} / \mathrm{cm}^{2}$, output fluences remain almost constant at about $1 \mathrm{~J} / \mathrm{cm}^{2}$ indicating that investigated sample shows good optical limiting behaviour.

Acknowledgements. Financial assistance from the Research Fund of Gülhane Medical Academy of Ankara and in part from Turkish Academy of Sciences (TUBA), from the Research Fund of Marmara University (Project No. Science107/020603), from Scientific and Technical Research Council of Turkey (TUBITAK, No. 105T708), from the Research Funds of Ankara University and Turkish State of Planning Organization (DPT) under grant number 2003K120190 are gratefully acknowledged. We also thank Dr. Ömür Çelikbıçak, research assistant, Hacettepe University, Department of Chemistry, Ankara for the assistance with some spectral data. 


\section{References}

1. Gutsche C.D. Calixarenes revisited. Monographs in Supramolecular Chemistry. London, RSC Publishing, 1998.

2. Higler I., Timmerman P., Verboom W., Reinhoudt D.N. Eur. J. Org. Chem. 1998, 2689-2702.

3. Liu J.-M., Zheng Y.-S., Zheng Q.-Y., Xie J., Wang M.-X., Huang Z.-T. Tetrahedron 2002, 58, 3729-3736.

4. Al-Saraierh H., Miller D.O., Georghiou P.E. J. Org. Chem. 2005, 70, 8273-8280.

5. Szemes F., Drew M.G.B., Beer P.D. Chem. Commun. 2002, 1228-1229.

6. Rincon A.M., Prados P., de Mendoza J. J. Am. Chem. Soc. 2001, 123, 3493-3498.

7. Diamond D., McKervey M. A. Chem. Soc. Rev. 1996, 25, 15.

8. Asfari Z., Weiss J., Vicens J. Synlett. 1993, 719.

9. Siepen A., Zett A., Vögtle F. Liebigs Ann., 1996, 757.

10. Rudkevich D.M., Verboom W., Reinhoudt D.N. J. Org. Chem. 1995, 60, 6585 .

11. Rebek J.Jr. Chem. Commun. 2000, 637.

12. For a review of $\mathrm{CH}-\pi$ interactions, see: Nishio M., Hirota M. Tetrahedron 1989, 45, 7201.

13. Maya E.M., Garcio-Frutos E.M., Vazquez P., Torres T. J. Phys. Chem. A 2003, 107, 2110.

14. Phthalocyanines: Properties and Applications (Leznoff C.C., Lever A.B.P., Edrs) Vols. 1-4, New York, VCH-Wiley, 19891996.

15. McKeown N.B. Phthalocyanine: Materials Synthesis, Structure and Function, Cambridge, Cambridge University Press, 1998.

16. Du X., Ma C., Hou X., Wang G., Li W., Du G. Heterocycles 2003, 60, 2535.

17. Moskalev P.N., Kirin I.S. Russ. J. Inorg. Chem. 1971, 16, 5760; ibid 1972, 46, 1019.

18. Nicholson M.M., Pizarello F.A. J. Electrochem. Soc., 1979, 126,1490

19. Corker G.A., Grant B., Clecak N.J. J. Electrochem. Soc. 1979, 126, 1339.

20. Simon J., Andre J.J. Molecular Semi-Conductors, Berlin, Springer 1985. Ch. 3.

21. Andre J. J., Holczer K., Petit P., Riou M. T., Clarisse C., Even R., Fourmigue M., Simon J. Chem. Phys. Lett. 1985, 115, 463466.

22. Turek P., Petit J.J., Andre J.J., Simon J., Even R., Boudjema B., Guillaud G., Maitrot M. J. Am. Chem. Soc. 1987, 109, 5119.

23. Maitrot M., Guillaud G., Boudjema B., Andre J.J., Strzelecka H., Simon J., Even R. Chem. Phys. Lett. 1987, 133, 59-62.

24 Meier H., Albrecht W., Wöhrle D., Jahn A. J. Phys. Chem. 1986, 90, 6349-6353.

25. Orimashi Y., Ohno H., Tsuchida E., Matsuda H., Nakanishi H., Kato M. Mol. Cryst. Liq. Cryst. 1988, 160, 139-149.

26. Louati A., El Meray M., Andre J. J., Simon J., Kadish K.M., Gross M., Giraudeau A. Inorg. Chem. 1985, 24, 1175-1179 and references given therein.

27. Ohta K., Jacquemin L., Sirlin C., Bosio L., Simon J. New J. Chem. 1988, 12, 751.

28. Simon J., Andre J.J., Skoulios A. Nouv. J. Chim. 1986, 10, 295-311.
29. Ceyhan T., Korkmaz M., Kutluay T., Bekaroğlu Ö. J. Porphyrins Phthalocyanines 2004, 8, 1383.

30. Ceyhan T., Korkmaz M., Erbil M.K., Bekaroğlu Ö. J. Porphyrins Phthalocyanines 2005, 9, 423-429.

31. Ceyhan T., Altındal A., Erbil M.K, Bekaroğlu Ö. Polyhedron 2006, 25, 737.

32. Ceyhan T., Altındal A., Özkaya A.R., Salih B., Bekaroğlu Ö. Chem. Commun. 2006, 320-322.

33. Ceyhan T., Altındal A., Özkaya A.R., Erbil M.K., Bekaroğlu Ö. Polyhedron 2007, 26, 73-84.

34. Kirin I.S., Moskalev P.N., Makashev A. Russ. J. Inorg. Chem. 1965, 10, 1065

35. Tomilova L.G., Chernykh E.V., Ioffe T.T., Luk'yanets E.A. $J$. Gen. Chem. USSR 1983, 53, 2339-2345.

36. Clarisse C., Riou M.T. Inorg. Chim. Acta. 1987, 130, 139-144.

37. Liu Y., Shigehara K., Yamada A. Thin Solid Films 1989, $303-$ 308.

38. De Cian A., Moussavi M., Fisher J., Weiss R. Inorg. Chem. 1985, 24, 3162-3167.

39. Liu W., Jiang J., Du D., Arnold D.P. Aust. J. Chem. 2000, 53, 131-135.

40. Jiang J., Kasuga K., Arnold D.P. In Supramolecular Photosensitive and Electro-active Materials (Nalwa H.S., Edr), New York, Academic Press, 2001, 113-210.

41. Toupance T., Bassoul P., Mineau L., Simon J. J. Phys. Chem. 1996, 100, 11704.

42. Toupance T., Ahsen V., Simon J. J. Am. Chem. Soc. 1994, $116,5352$.

43. Pandoven A., Cozien Y., L'Her M. New. J. Chem. 1991, 15, 515.

44. Konami H., Hatano M., Tajiri A. Chem. Phys. Lett. 1989, 160, 163.

45. Battisti D., Tomilova L., Aroca R. Chem. Mater. 1992, 4, 1323

46. Ricciardi G., Belviso S., Leli F., Ristori S. J. Porphyrins Phthalocyanines 1998, 2, 177.

47. Tomilova L. G., Dyumaev K. M. Mendeleev Commun. 1995, 109.

48. Sleven J., Görller-Walrand C., Binnemans K. Mater. Sci. Eng. C 2001, 18, 229-38.

49. Chen Y., Liu H.-G., Pan N., Jiang J. Thin Solid Films 2004, 460, 279-285.

50. Martynov A.G., Gorbunova Y.G. Inorg. Chim. Acta 2007, $360,122-130$.

51. Nevin W. A., Liu W., Hempstead M. R., Marcuccio S. M., Melnik M., Leznoff C.C, Lever A.B.P. Inorg. Chem. 1987, 26, 891.

52. Sheik-bahae M., Said A.A., Van Stryland E.W. Opt. Lett. 1989, 14, 955.

53. Sheik-bahae M., Said A.A., Wei T.H., David D.H., Van Stryland E.W. IEEE J. Quantum Electron. 1990, 26, 760.

54. Coulter D. R., Miskowski V.M., Perry J.W., Wei T.H., Van Stryland E.W., Hagan D.J. SPIE Proc. 1989, 1105, 42.

55. Kwak C.H., Lee Y.L., Kim S.G. J. Opt. Soc. Am. B 1999, 16, 600.

56. O'Flaherty S.M., Hold S.V., Cook M.J., Torres T., Chen Y., Hanack M., Blau W.J. Adv. Mater. 2003, 15, 19.

57. Slodek A., Wöhrle D., Doyle J.J., Blau W. Macromol. Symp., 2006, $235,9$. 